\title{
Evaluation of Welding Parameter's Effects on Corrosion Behavior of Bronze-Carbon Steel Dual-Layer Explosion Welded Joint at Salt Enviroment
}

\author{
Mohammad Reza Khanzadeh Ghareh Shiran ${ }^{a *}$, Mohammad Razazi ${ }^{a}$, Hamid Bakhtiari ${ }^{b}$, Ali Tavira ${ }^{a}$ \\ ${ }^{a}$ Center for Advanced Engineering Research, Majlesi Branch, Islamic Azad University, Isfahan, Iran \\ ${ }^{b}$ Advanced Materials Research Center Department of Materials Engineering, Najafabad Branch, \\ Islamic Azad University, Najafabad, Isfahan, Iran
}

Received: July 04, 2017; Revised: November 10, 2017; Accepted: November 10, 2017

\begin{abstract}
In the current investigation, corrosion behavior and microstructural variations of explosion-welded joint of bronze-carbon steel dual-layer plates were studied. The resultant curves of potentiodynamic's polarization tests demonstrated that the lowest corrosion rate was related to the sample with maximum explosive load thickness, and the highest corrosion speed was for the sample with minimum standoff distance. EIS test results of welded samples were indicative of creating a passive layer at the beginning of immersion process which showed that the polarization resistance has been reduced by increasing of explosive load thickness. So, the corrosion mechanism included two stages; at the beginning of immersion, for the samples with the lower thickness of explosive load, a passive layer would be created around the component due to higher concentration gradient and then, by removing of this layer, the galvanic couple determines the corrosion rate.
\end{abstract}

Keywords: explosion welding, explosive load thickness, intensive plastic deformation, Vortex

\section{Introduction}

Explosion welding is a process that utilizes the explosion energy to form a metallurgical bond by electron sharing among two components which kept at specified standoff distance. Two welding surfaces approach together with very high localized pressure when the collision occurs. As a result of the collision between the surfaces, local pasty area forms at the interface which causes the joining. Due to high collision pressure, a high-speed jet will be created from each joint surfaces which form a clean joint interface and removes the surface pollutions. Forming of the jet is the basic cause of suitable bonding in explosion welding. This welding process is a non-fusion route (solid-state) that used to join and cladding the similar and dissimilar metals, industrially, in the forms of dual or multilayers. Due to lack of direct heating during this process, the welded joints have not the defects of fusion welding methods, hot rolling and hot forging joints ${ }^{1-4}$. Very low investigations were performed about the corrosion behavior of explosion-welded joints that as following: Kengkla and Tarlp $p^{5}$ studied the effect of intermetallic compounds on corrosion behavior of threeply explosion welded joint of aluminum/steel for military industries. Their results demonstrated that the forming of intermetallic compounds of $\mathrm{Al}_{3} \mathrm{Fe}$ and $\mathrm{Al}_{5} \mathrm{Fe}_{2}$ at joint interface caused a cathodic potential toward aluminum and anodic potential to steel. Therefore, preferred corrosion attack near to aluminum boundary and intermetallic compounds has happened. Moudaly and cooperators ${ }^{6}$ investigated the

*e-mail:khanzade@gmail.com corrosion behavior of 304 stainless steel- titanium explosion welded joint. The results presented that the bending strength of joint was in a normal range at the nitric acid environment and the corrosion attack mainly occurred at the joint interface. Acarier ${ }^{7}$ investigated the corrosion behavior of aluminumcopper explosion welded joint. The results are indicative of that the galvanic corrosion occurred at the joint interface and the aluminum part of joint had a more anodic potential rather than the copper part due to higher electronegativity, so the corrosion attack mostly occurred at the aluminum component. Kahrman and partners ${ }^{8}$ studied the corrosion behavior of stainless steel-titanium explosion welded joint. The results showed that the increasing of explosive load amount at a corrosive environment caused the mass increasing of joined sheets due to more intensive plastic deformation and forming an oxide layer on the surface. They also ${ }^{9}$ studied the corrosion behavior of aluminum-titanium alloy (Ti-6Al-4V) explosion welded joint. The corrosion test results revealed that the materials mass reduction rate was high at first and decreased then. Also, the increase of plastic deformation amount that was due to the increase of explosive load amount caused the reduction of samples mass in corrosion test. Zarei and partners ${ }^{10}$; compared the corrosion behavior of fusion and explosion welded joints of carbon steel-Inconel 625 . The comparison results showed that the corrosion resistance of fusion welded joint was more inhomogeneous rather than explosion welded joint due to chemical non-similarity caused by segregation and forming of destructive secondary phases and their aggregation for fusion welded joint which prevented the forming of a constant passive layer. 
Dissimilar joints such as bronze-St37 steel explosion welded joint are utilized for agricultural and industrial instruments, so studying their joint behavior is significant.

In the present study, the influence of explosive material thickness and the standoff distance of bronze and ST37 steel explosion welded joint on metallurgical structure, corrosion behavior of interface intermetallic compounds and joints mechanical properties, have been investigated. Corrosion properties have been researched for the joint area at $\mathrm{NaCl}$ (3.5 wt. \%) solution and the relationship between microstructure and interface hardness with corrosion behavior was analyzed.

\section{Experimental Procedure}

In this research, a bronze sheet was used as the flyer plate with the dimension of $150 \mathrm{~mm} \times 150 \mathrm{~mm}$ with the thickness of $2 \mathrm{~mm}$ and the $\mathrm{St} 37$ carbon steel as the base plate with dimensions of $150 \mathrm{~mm} \times 150 \mathrm{~mm}$ with the thickness of 4 $\mathrm{mm}$. The chemical composition of used alloys is given in Table 1. Explosive material was a kind of 95/5 amatol with the composition of $5 \mathrm{wt}$. \% TNT and $95 \%$ of ammonium nitrate with the detonation velocity of $2507 \mathrm{~m} / \mathrm{s}$. The kind of detonator was M8. Fig. 1 shows the primary arrangement of the plates for explosion welding. To the establishment of two plates for explosion welding, a concrete platform was used as a buffer layer and covered media which covered with soft sand. Also, copper wires with suitable diameters which had heights such designed standoff distances that kept between bronze and steel sheets were used to set the specified designed distance for each test. The velocity of explosive material was measured by the Fiber-Optic system. Explosion welding parameters are presented in Table 2 for 4 samples; the standoff distance was 50 to $100 \%$ of flyer plate and the thickness of the explosive material were adjusted to form enough collision kinetic energy.

\subsection{Tests}

\subsubsection{Microstructure evaluation of joint using optical microscope and scanning electron microscope}

Some samples were prepared with the dimension of $1 \mathrm{~cm} \times 1 \mathrm{~cm}$ using a wire cut device which was parallel to explosion front. Three devices of mount press, polish, and optical microscope were used in the metallographic process.

The mounted samples were sanded by papers of 120 to 1500 grades and the final polish was performed by diamond paste solution and muffler. After polishing the samples, they were etched at nital ( $2 \%$ ) solution for 8 seconds at steel side of joint to be analyzed by OM.
Also, local solidified area and their compounds at joint interfaces were analyzed by SEM equipped with EDS (Energy Dispersive X-ray spectrometry) analysis system.

\subsubsection{Microhardness test}

Microhardness tests (Vickers) were performed by micro hardness measurement device (model: INNOVA TEST) with applied load of $200 \mathrm{~g}$ for 10 seconds. Afterward, the diameter of the square-shape edge of the sunken surface was measured and calculated, strictly. Fig. 2 is shown the form of hardness measurement.

\subsubsection{Electrochemical measurements}

DC and AC electrochemical measurements were performed with AUTOLAB model PGSTAT $302 \mathrm{~N}$ potentiostat using samples with a surface area of $1 \mathrm{~cm}^{2}$ at room temperature $\left(25^{\circ} \mathrm{C}\right)$. A three-electrode cell was used for electrochemical measurements; the working electrode was the test material whereas a saturated calomel electrode (SCE) was used as the reference electrode and a platinum gauze was used as the counter electrode. Anodic polarization measurements were performed at a scan rate of $1 \mathrm{mV} / \mathrm{s}$, from- $250 \mathrm{mV}$ to $+250 \mathrm{mV}$ with respect to the open circuit potential (OCP). Electrochemical impedance spectroscopy (EIS) measurements were performed at the frequency ranged from $10 \mathrm{KHz}$ to $10 \mathrm{mHz}$ with five points/decade and an amplitude of sinusoidal wave of $10 \mathrm{mV}$.

\section{Results and discussion}

\subsection{Joints microstructure evaluation by optical microscope}

Fig. 3 is shown the optical microscope images at the longitudinal direction of joint in the form of waves. As seen, the joint interface has wavelike form in this condition. Due to higher explosive load thickness of this sample (with the standoff distance of $2 \mathrm{~mm}$ and explosive load thickness of $45 \mathrm{~mm}$ ) compared to $2^{\text {nd }}, 3^{\text {rd }}$ and $4^{\text {th }}$ sample series, it had the higher thickness of solidified liquid layer. In explosion welding, two solidified joint interfaces of metal-metal and metal-liquid could be formed at the joint interface. Flyer plate's minimum velocity also has the minimum amount of collision kinetic energy which is essential for joining; As a result of Flyer plate's collision, consumable kinetic energy changes to potential energy that finally causes the plastic deformation of collision surface. If the plastic deformation amount would not be enough, the short waves will be formed and the local liquid area would not appear. Increasing of collision kinetic energy causes an intensive

Table 1. Chemical composition of bronze and St37 carbon steel

\begin{tabular}{|c|c|c|c|c|c|c|c|c|c|c|c|}
\hline Element (\% w.t) & $\mathrm{N}$ & $\mathrm{Zn}$ & $\mathrm{S}$ & $\mathrm{P}$ & $\mathrm{Pb}$ & $\mathrm{Sn}$ & $\mathrm{Cu}$ & $\mathrm{C}$ & $\mathrm{Fe}$ & $\mathrm{Mn}$ & $\mathrm{Si}$ \\
\hline steel - ST 37 & 0.009 & - & 0.04 & 0.04 & - & - & - & 0.17 & Base & 0.7 & 0.3 \\
\hline bronze & - & 0.119 & - & 0.0892 & 0.0123 & 5.92 & 93.8 & - & 0.0595 & - & - \\
\hline
\end{tabular}




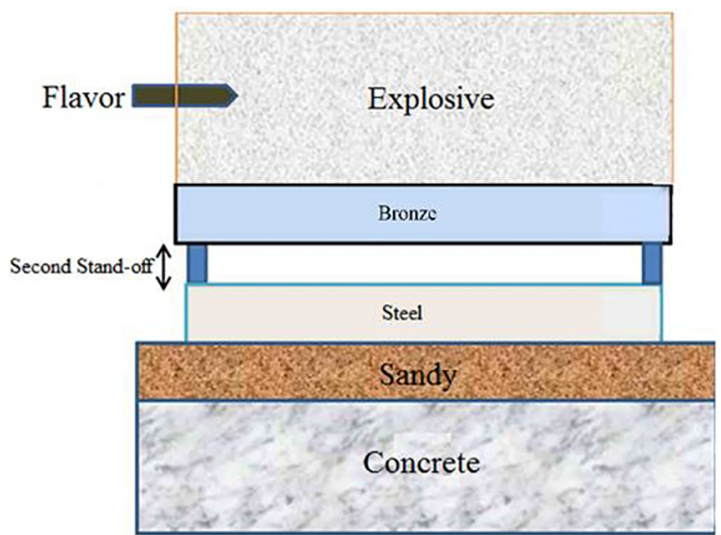

Figure 1. primary adjustment of welding plates to perform explosion welding

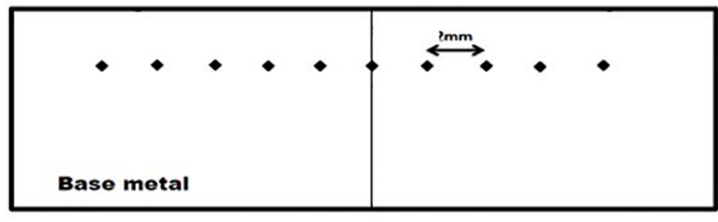

Figure 2. Form and distance of hardness measurement
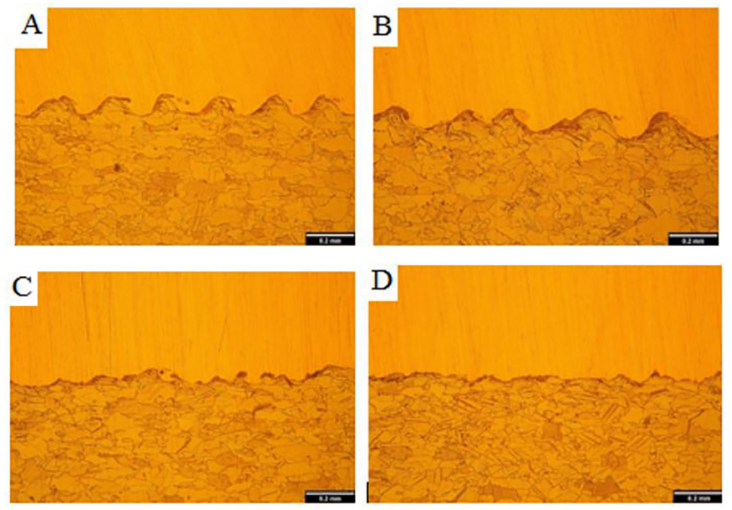

Figure 3. Optical metallographic images of joint interface (100 X) for a) $1^{\text {st }}$ sample, b) $2^{\text {nd }}$ sample, c) $3^{\text {rd }}$ sample and d) $4^{\text {th }}$ sample

Table 2. welding parameters

\begin{tabular}{lcc}
\hline Sample No. & $\begin{array}{c}\text { Standoff distance } \\
(\mathrm{mm})\end{array}$ & $\begin{array}{c}\text { Explosive material } \\
\text { thickness }(\mathrm{mm})\end{array}$ \\
\hline 1 & 2 & 45 \\
2 & 2 & 30 \\
3 & 2 & 20 \\
4 & 1.5 & 20 \\
\hline
\end{tabular}

plastic deformation at beneath and the peak of the wave. As a result of higher collision pressures, the Vortexs can be formed at the joint interface and they would be able to create local liquid areas at some vicinity of the interface. These areas could be formed by internal heating which created by higher pressure from explosion shocking waves and intensive plastic deformation; also the production of adiabatic heat could because of sticking Vortexs at ahead of some wave fronts which cause transmutation of kinetic energy to thermal energy during the collision. Also, the adiabatic heat could be produced by trapped gasses between plates. These areas surrounded by around cold metal and they would be under a high solidification velocity of $10^{5}-10^{7} \mathrm{~K} / \mathrm{S}^{1}$.

According to the Fig. 3 , the thickness of local solidified liquid layer of $3^{\text {rd }}$ series of joint interfaces has been decreased compared to $2^{\text {nd }}$ series of samples with constant standoff distance $(2 \mathrm{~mm})$. Due to lower thickness of explosive load compared to $1^{\text {st }}$ and $2^{\text {nd }}$ series of samples, the height of waves and grains were decreased. Increasing of collision velocity caused the improvement in collision pressure and the collision dynamic angle and consuming kinetic energy were increased at the collision point. Some parts of consuming kinetic energy were converted to potential energy at joint interface and caused sheets to more deform along the collision surface; so increasing of consuming kinetic energy lead to more plastic deformation at the joint interface and this increase caused the material behavior tend to be more fluent. Jumper plate velocity has been increased by mounting of standoff distance and explosive material thicknesses; also, due to the difference of density and velocity of waves in metals, pressing waves at two sides of the joint interface were changed by the increase of flyer plate velocity and finally the collision point was vibrated during joining. These oscillations were increased by enhancement of collision velocity and more volume of materials loosed their strength in adjacency of collision point and showed a plastic trend like a fluid. As seen in Fig. 3, $4^{\text {th }}$ series of sample's wave's height and length were decreased compared to $3^{\text {rd }}$ series of samples due to lower standoff distance.

\subsection{Microstructure evaluation of samples by SEM}

\subsubsection{Microstructure evaluation of $1^{\text {st }}$ sample series}

Fig. 4 is shown the scanning electron microscopy images of the local liquid layer of $1^{\text {st }}$ series of samples. The thickness of the local liquid layer is specified in the figure. Due to higher explosive load thickness and collision kinetic energy of the joint interface, almost the all thickness of solidified liquid layer was increased. EDS Analysis of local solidified liquid layer of the interface is presented in Fig. 4. The EDS result showed that the solidified liquid layer chemical composition

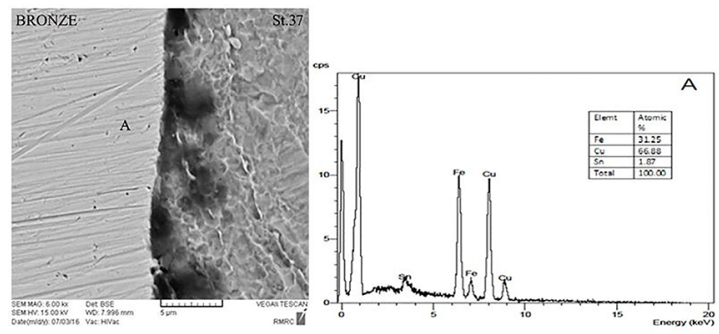

Figure 4. SEM images and EDS analysis of specified local solidified liquid areas at interfaces of $1^{\text {st }}$ series of samples 
included 31.25 at. \% of $\mathrm{Fe}, 66.88$ at. \% of $\mathrm{Cu}$ and 1.87 at. \% of tin; the main reason of this composition related to forming the local solidified liquid layer area and combining of the base and flyer plates due to rotation of trapped jumper jet at the joint interface ${ }^{11}$.

\subsubsection{Microstructure evaluation of $2^{\text {nd }}$ series of samples}

Fig. 5 is shown the scanning electron microscopy images of the local liquid layer of $2^{\text {nd }}$ series of samples with the standoff distance of $2 \mathrm{~mm}$ and explosive load thickness of $30 \mathrm{~mm}$. The thickness of the local liquid layer is specified in the figure. Higher explosive load thickness and collision kinetic energy of the joint interface, are the reasons for the thickness increase of solidified liquid layer. SEM image and EDS Analysis of local solidified liquid layer of interface for point $A$ are presented in Fig. 5. The EDS result showed that the solidified liquid layer chemical composition included 35.02 at. $\%$ of $\mathrm{Fe}, 63.35$ at. $\%$ of $\mathrm{Cu}$ and 1.45 at. $\%$ of tin.

\subsubsection{Microstructure evaluation of $3^{\text {rd }}$ series of samples}

Fig. 6 is shown the scanning electron microscopy images of the local liquid layer and joint interface of $3^{\text {rd }}$ series of

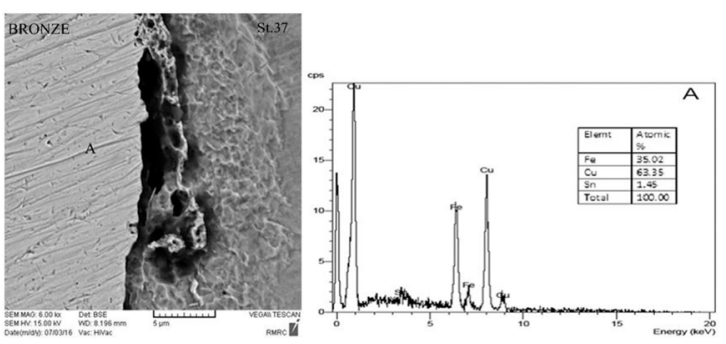

Figure 5. SEM images and EDS analysis of specified local solidified liquid areas at interfaces of $2^{\text {nd }}$ series of samples

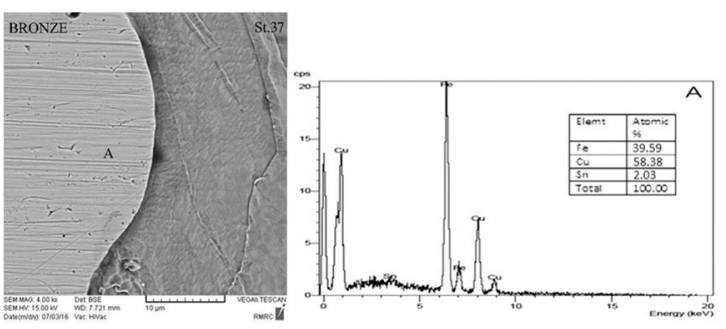

Figure 6. SEM images and EDS analysis of specified local solidified liquid areas at interfaces of $3^{\text {rd }}$ series of samples

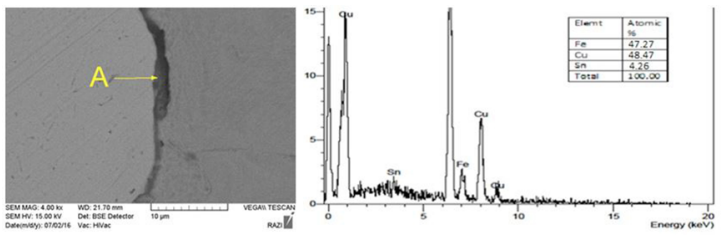

Figure 7. SEM images and EDS analysis of specified local solidified liquid areas at interfaces of $4^{\text {th }}$ series of samples samples. The thickness of local liquid layer for this sample is higher than the thickness for $4^{\text {th }}$ series of samples. According to the figure, $3^{\text {rd }}$ series of samples have welding standoff distance of $2 \mathrm{~mm}$ and explosive load thickness of $20 \mathrm{~mm}$ that their wave's heights are higher than the $4^{\text {th }}$ series due to higher standoff distance. Fig. 6 is shown the EDS Analysis of the local liquid layer that the chemical composition included 39.59 at. $\%$ of $\mathrm{Fe}, 58.38$ at. $\%$ of $\mathrm{Cu}$ and 2.03 at. $\%$ of tin.

\subsubsection{Microstructure evaluation of $4^{\text {th }}$ series of samples}

Fig. 7 is shown the scanning electron microscopy images of the local liquid layer and joint interface of $4^{\text {th }}$ series of samples with the standoff distance of $1.5 \mathrm{~mm}$ and explosive load thickness of $20 \mathrm{~mm}$. The thickness of local liquid layer for this sample is low because of lower standoff distance and local liquid layer thickness. Fig. 7 presents the EDS Analysis of the local liquid layer at point $A$ with the composition of 47.27 at. $\%$ of $\mathrm{Fe}, 48.47$ at. $\%$ of $\mathrm{Cu}$ and 4.26 at. $\%$ of tin.

\subsection{Mechanical properties evaluation}

\subsubsection{Micro hardness test}

In explosion welding, flyer and base plates are exposed to intense stress wave due to the explosive material explosion. These intense stresses cause some changes in metallurgical properties and finally lead to increase the microhardness. Microhardness is a function of chemical compositions,

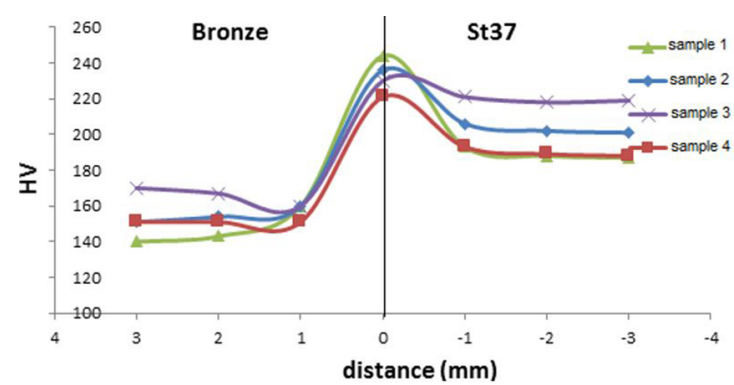

Figure 8. Hardness profile of explosion welded samples

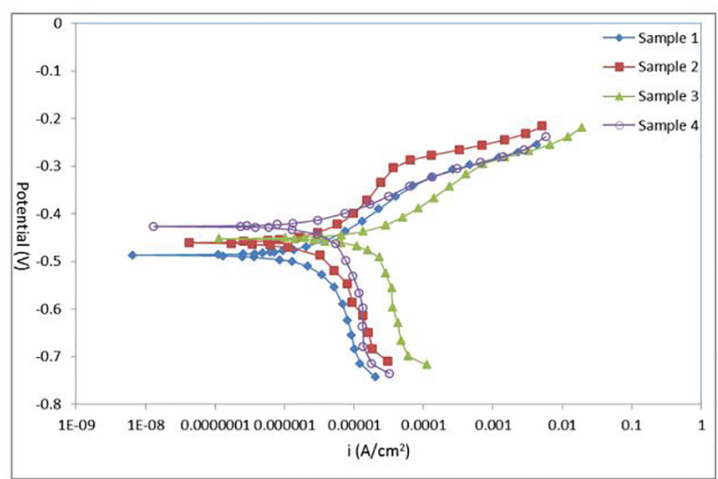

Figure 9. Potentio-dynamic polarization curves for explosion welded samples 
percent of alloying elements, inter-metallic compounds, heat changes, explosive load and standoff distance.

According to results, shocking hardening would be happened due to explosion waves, microhardness has been increased by approaching to the joint interface Fig. 8. Due to the higher thickness of explosive material, first sample had the most hardness amount (244 HV); $2^{\text {nd }}$ and the $3^{\text {rd }}$ samples had the hardness amount of 236 and 230 Vickers, in order. Joint interface hardness reduction for $4^{\text {th }}$ sample rather than the $3^{\text {rd }}$ sample was due to increase of explosive load raise which caused an enhancement in flyer plate velocity and Dynamic angle of collision for the samples with higher standoff distance; due to increasing of standoff distance, kinetic energy would grow and an intense plastic deformation occurred at joint interface and shock-hardening would be happened due to explosion waves.

\subsection{Potentiodynamic polarization test results}

Fig. 9 is shown the curves of polarization test for explosion welded samples. Extracted electrochemical parameters from these curves are reported in Table 3 that are included of corrosion potential $\left(\mathrm{E}_{\text {corr }}\right)$, corrosion current density $\left(\mathrm{I}_{\text {corr }}\right)$ (corrosion speed), anodic and cathodic Tafel values which were obtained by Tafel extrapolation method.

In general, being the parallel of cathodic Tafel branches in Fig. 9 are described that the hydrogen dispersion was under control of the activation process and the reduction mechanism of $\mathrm{H}+$ ions on samples surfaces was not very affected by joining process. According to Fig. 9, the anodic branches were different from each other and they were affected by explosion welding parameters. For all the samples, a very poor passive layer was formed at the potential of the corrosive environment which was removed by potential increase of this layer, quickly. The $4^{\text {th }}$ sample had the most protective layer that created on the surface after immersion; the reason was due to the more potential gradient of the steel-bronze galvanic couple (Fig. 10) rather than the other samples; this potential gradient caused more exchanging current density and creating a layer as a result of corrosion products, instantly. Corrosion potential and corrosion current density (corrosion speed) were distinct from each other before joining of two alloys at $\mathrm{NaCl}(3.5 \%)$ environment; the bronze part had lower corrosion rate rather than the steel at salt environment. After joining of the alloys, corrosion potential and corrosion

Table 3. Extracted electro-chemical parameters from potentiodynamic polarization curves for explosion welded samples at $\mathrm{NaCL}$ (3.5\%) solution and room temperature.

\begin{tabular}{lcccc}
\hline Sample & $\begin{array}{c}\boldsymbol{I}_{\text {corr }} \mu \mathrm{A} \\
\mathrm{cm}^{-2}\end{array}$ & $\boldsymbol{E}_{\text {corr }}(\mathrm{mV})$ & $\begin{array}{c}\boldsymbol{\beta}_{\mathrm{a}}(\mathrm{mV} \\
\left.\mathrm{dec}^{-1}\right)\end{array}$ & $\begin{array}{c}\boldsymbol{\beta}_{\mathrm{c}}(\mathrm{mV} \\
\left.\mathrm{dec}^{-1}\right)\end{array}$ \\
\hline 1 & 4.26 & -459 & 84.7 & 50.5 \\
2 & 10.90 & -462 & 74 & 49 \\
3 & 16.37 & -414 & 81 & 53 \\
4 & 15.02 & -426 & 76 & 75 \\
\hline
\end{tabular}

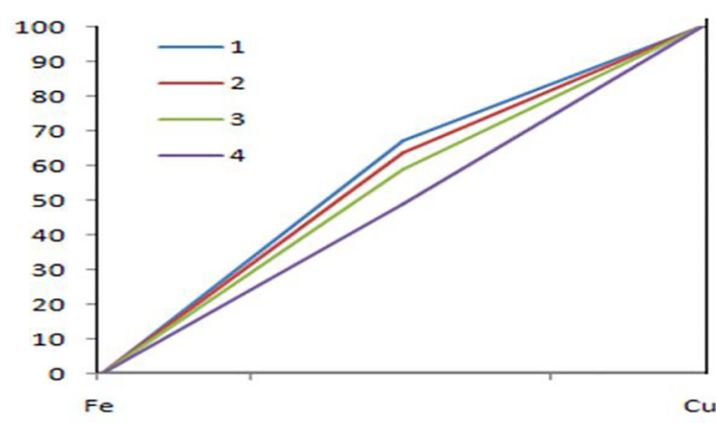

Figure 10. Resultant concentration potential gradient from EDS analysis (part 2.4) of sample's interfaces ( $\left({ }^{\text {st }}\right.$ series to $4^{\text {th }}$ series)

speed have reached to some new values of equilibrium which the values were between the corrosion speed and corrosion potential before joining at the corrosive environment that is depended on the concentration of alloy's interface after joining ${ }^{12,13}$. Comparing of $4^{\text {th }}$ sample and the others on basis of iron chemical concentration gradient (Fig. 10), it can be concluded that the corrosion behavior of $4^{\text {th }}$ sample was similar to the corrosion behavior of steel due to more concentration of iron at interface before joining and so the corrosion current density (corrosion speed) of this sample was higher rather than others. On the obtained results of optical microscope (Fig.3) and potentiodynamic polarization test, it can be concluded that the $1^{\text {st }}$ sample had more local liquid layer than others due to higher explosive load thickness that caused the reduction of concentration gradient (Fig. 10) between two joined alloys; so the galvanic couple effects would be lowered, significantly.

\subsection{Results of electrochemical impedance spectroscopy}

An electrochemical impedance spectroscopy (EIS) analysis was performed to evaluate the created surficial layer of samples at the corrosive environment. Nyquist diagrams of explosion-welded samples are presented in Figure 11.

EIS analysis data were obtained using equivalent circuit presented in Fig. 12 which is in accordance with experimental results; they are given in Table 4.

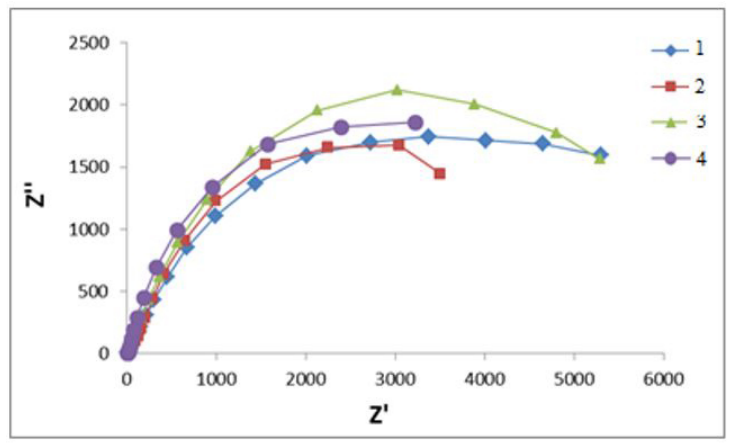

Figure 11. Nyquist curves of explosion welded samples 


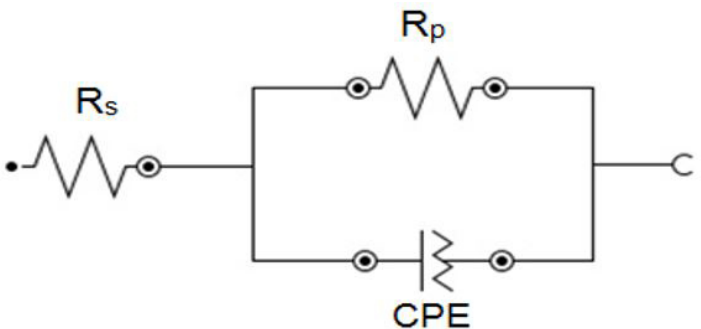

Figure 12. Used electrical equivalent circuit diagram for modeling of solution/metal interface behavior.

It is obvious from the Fig. 11 that the obtained impedance circuits in Nyquist curve were a little mangled than a complete hemicycle which known as the prolapse effect phenomenon. Generally, the diversion from the complete hemicycle is related to the frequency dispersion, the surface roughness, and the mass sharing resistance. This diversion is described with the non-ideal behavior of dual layer as a capacitor. Therefore, it is essential to use a constant phase element (CPE) instead of capacitor non-ideal behavior of dual layer due to distribution of relaxation time caused by the available surface roughness (Micro or Nano) such as boisterous, porous layer, impurities, preventing absorption, diffusion and etc. to obtain more precise accordance. The impedance of a constant phase element is delineated by the following equation:

$$
\mathrm{Z}_{\mathrm{CPE}}=\left[Y_{0}(j \omega)^{\mathrm{n}}\right]^{-1}
$$

Where the $\mathrm{Y}_{0}$ is relativism factor (admittance) and the $\mathrm{n}$ is surface roughness coefficient (phase variance). CPE shows pure resistance, pure capacitance and pure inductive behaviors for the $\mathrm{n}$ amounts of 0,1 and -1 , in order ${ }^{12}$.

In present study, Nyquist curves diameters (Fig. 11) are considered as the polarization resistance $\left(\mathrm{R}_{\mathrm{p}}\right)$; in other words, they are the only available capacitance circuits that as to charge transition resistance between the metal and external Helmholtz layer (OHP). These observations proved that the metallic corrosion is controlled by a load sharing process.

The electrical dual layer can be described well by an equivalent circuit and presenting a proper model of solution/ metal interface. The corresponding electrical equivalent circuit for the samples at a solution (Fig. 13.a) is presented by a schematic model of potential distributions at metal/solution interface (Fig. 13.b) and also the dual layer resistances (Fig. 13.c) in Fig. 13. In the presence of interceptors, the polarization resistance $\left(\mathrm{R}_{\mathrm{p}}\right)$ consists of charge transition $\left(\mathrm{R}_{\mathrm{ct}}\right)$, preventing layer resistance on the metal surface $\left(R_{f}\right)$, all the stored particles (preventing molecules, corrosion products and etc.) at solution/metal interface $\left(\mathrm{R}_{\mathrm{a}}\right)$ and diffusion layer resistance $\left(\mathrm{R}_{\mathrm{d}}\right):\left(\mathrm{R}_{\mathrm{p}}=\mathrm{R}_{\mathrm{ct}}+\mathrm{R}_{\mathrm{f}}+\mathrm{R}_{\mathrm{a}}+\mathrm{R}_{\mathrm{d}}\right)^{12}$.

The capacity of dual layer $\left(\mathrm{C}_{\mathrm{d} 1}\right)$ is calculated as following:

$$
f\left(-Z_{\max }^{\prime \prime}\right)=\frac{1}{2 \pi C_{\mathrm{dl}} R_{\mathrm{ct}}}
$$

Table 4. EIS resultant data of explosion welded samples at $\mathrm{NaCl}$ $(3.5 \%)$ solution and room temperature

\begin{tabular}{lcccc}
\hline Sample & $\boldsymbol{R}_{\mathrm{s}}(\Omega)$ & $\boldsymbol{R}_{\mathrm{p}}\left(\Omega \mathrm{cm}^{2}\right)$ & $\boldsymbol{C}_{\mathrm{dl}}(\mu \mathrm{F} \mathrm{cm})$ & $\boldsymbol{n}$ \\
\hline 1 & 11.33 & 5771 & 138 & 0.8 \\
2 & 17.72 & 4997 & 155 & 0.75 \\
3 & 10.72 & 6306 & 71 & 0.8 \\
4 & 11.55 & 6288 & 150 & 0.77 \\
\hline
\end{tabular}

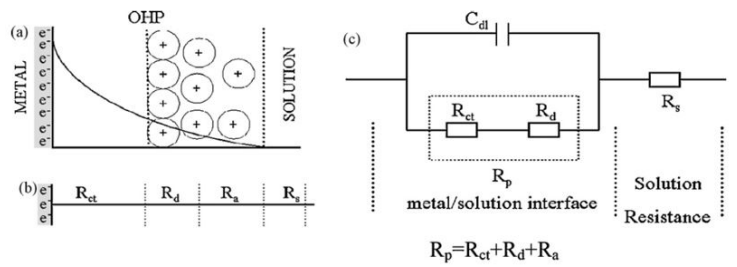

Figure 13. Potential distributions at (a) metal/solution interface, (b) resistances corresponding to dual layer and (c) proposal electrical equivalent circuit for non-preventing solution ${ }^{13}$

Where in this relation, $-Z^{\prime \prime}{ }_{\max }$ is the maximum value of impedance imaginary component.

Table 4 presents the results of electrochemical impedance spectroscopy of explosion-welded samples at $\mathrm{NaCl}$ (3.5 $\%)$ solution after 90 minutes of immersion. The highest polarization resistance was related to the $3^{\text {rd }}$ sample series equals to $6306 \Omega . \mathrm{cm}^{2}$ and after that, the $4^{\text {th }}$ sample was 6288 $\Omega . \mathrm{cm}^{2}$; the lowest amount was for the $2^{\text {nd }}$ sample series. According to EDS analysis results at $4^{\text {th }}$ sample interface, it can be concluded that the layer of metal with high current density would be attacked at corrosive environment during immersion of alloy due to higher concentration potential gradient which caused by high galvanic couple of steel and bronze, so the corrosion products will be created on the metal surface; the higher concentration gradient will cause stronger created protective layer. Therefore, the formed passive layer of $4^{\text {th }}$ sample possessed more polarization resistance than $2^{\text {nd }}$ sample series. The test results of polarization resistance for $3^{\text {rd }}$ and $4^{\text {th }}$ samples were very close to each other.

Comparison of potentiodynamic polarization and EIS test results showed that the corrosion resistance of $4^{\text {th }}$ sample was higher at the beginning of immersion process due to resistant passive layer forming; however, by passing of time the mentioned layer would be removed. The corrosion rate of $1^{\text {st }}$ sample series was lower than the other samples because of lower concentration potential gradient. So, the corrosion mechanism of the steel-bronze coupled alloys at corrosive environment was dependent on formed passive layer on surface and concentration potential gradient at interfaces of samples.

\section{Conclusion}

In the current study, corrosion behavior and microstructure evaluation of explosion-welded St 37 steel and bronze sheets with different welding standoff distances and explosive 
load thicknesses, were studied and the following results were obtained:

1. Increase of standoff distance and explosive material thickness caused to form Vortex-shaped joint interface and the local solidified liquid areas were created due to enhancement of collision pressure at vicinity of interface Vortex waves; the chemical composition of these areas included a mix of alloying elements of flyer and base plates which combined due to rotation of jumper jet.

2. Microhardness test result showed that the hardness amount of samples were higher for areas closer to the joint interface (weld metal) rather than the base metal areas due to shock-hardening which caused as a result of the collision. By increasing of standoff distance and explosive material thickness, the hardness amount has been increased. Hardness amount of the sample with $45 \mathrm{~mm}$ of explosive material thickness was about $244 \mathrm{~V}$ and for the sample with $20 \mathrm{~mm}$ of explosive material the amount decreased to $230 \mathrm{~V}$.

3. The obtained results of potentiodynamic polarization and EIS tests showed that a protective layer was formed on the surface at the beginning of immersion process due to distinct potential gradient of two dissimilar metals; according to the Nyquist curve of $4^{\text {th }}$ sample series and the corresponding polarization diagram, higher concentration gradient would form a stronger layer; however, after removing of the passive layer, the controlling corrosion mechanism would be the potential difference amount of the joint, so the sample with standoff distance of $2 \mathrm{~mm}$ and explosive material thickness of $45 \mathrm{~mm}$ had lower corrosion current density rather than other samples due to lower potential gradient obtained by EDS analysis.

\section{References}

1. Crossland B. Explosive Welding of Metals and Its Applications. Oxford: Clarendon Press; 1982.

2. Blazynski TZ. Explosive Welding, Forming and Compaction. Dordrecht: Springer Netherlands; 1983.

3. Benák M, Turňa M, Ožvold M, Nesvadba P, Lokaj J, Čaplovič L, et al. Study of Al-austenitic steel boundary formed by explosion welding. In:
METAL 2010: 19. Mezinárodní Konference Metalurgie a Materiáli̊; 2010 May 18-20; Rožnov pod Radhoštěm, Czech Republic.

4. Shiran MRKG, Bakhtiari H, Mousavi SAAA, Khalaj G, Mirhashemi SM. Effect of Stand-Off Distance on the Mechanical and Metallurgical Properties of Explosively Bonded 321 Austenitic Stainless Steel - 1230 Aluminum Alloy Tubes. Materials Research. 2017;20(2):291-302.

5. Kengkla N, Tareelap N. Role of Intermetallic Compound on Corrosion of Aluminium/Steel Transition Joint Used in Naval Applications. In: Proceedings of the $1^{\text {st }}$ Mae Fah Luang University International Conference 2012 (MFUIC2012) on the Future Challenges Towards ASEAN Integration; 201229 Nov-1 Dec; Chiangrai, Thailand.

6. Mudali UK, Rao BMA, Shanmugam K, Natarajan R, Raj B. Corrosion and microstructural aspects of dissimilar joints of titanium and type 304L stainless steel. Journal of Nuclear Materials. 2003;321(1):40-48.

7. Acarer M. Electrical Corrosion, and Mechanical Properties of Aluminum-Copper Joints Produced by Explosive Welding. Journal of Materials Engineering and Performance. 2012;21(11):2375-2379.

8. Kahramana N, Gülenç B, Findik F. Joining of titanium/stainless steel by explosive welding and effect on interface. Journal of Materials Processing Technology. 2005;169(2):127-133.

9. Kahramana N, Gülenç B, Findik F. Corrosion and mechanicalmicrostructural aspects of dissimilar joints of Ti-6Al-4V and Al plates. International Journal of Impact Engineering. 2007;34(8):1423-1432.

10. Rajani HRZ, Mousavi SAAA, Sani FM. Comparison of corrosion behavior between fusion cladded and explosive cladded Inconel 625/plain carbon steel bimetal plates. Materials \& Design. 2013;43:467-474.

11. Murr LE, Ferreyra E, Pappu TS, Garcia EP, Sanchez JC, Huand W, et al. Novel deformation processes and microstructures involving ballistic penetrator formation and hypervelocity impact and penetration phenomena. Materials Characterization. 1996;37(5):245-276.

12. Stansbury EE, Buchanan RA. Fundamentals of Electrochemical Corrosion. Materials Park: ASM International, 2000. 487 p.

13. Verma J, Taiwade RV. Dissimilar welding behavior of $22 \% \mathrm{Cr}$ series stainless steel with $316 \mathrm{~L}$ and its corrosion resistance in modified aggressive environment. Journal of Manufacturing Processes. 2016;24(Pt 1):1-10. 